\title{
Factors Affecting the Clinical Practice of Nursing Interns at Tertiary Hospital Jeddah in Saudi Arabia
}

\author{
Hend Al Najjar ${ }^{1} \&$ Hawazen Rawas ${ }^{1}$ \\ ${ }^{1}$ College of Nursing, University of King Saud bin Abdul Aziz University, Um Salem Street, Jeddah, Kingdom of \\ Saudi Arabia \\ Correspondence: Hend Al Najjar, Associate Dean of Academic Affairs, College of Nursing, University of King \\ Saud bin Abdul Aziz University, Um Salem Street, Jeddah, Kingdom of Saudi Arabia.
}

Received: August 10, 2018

Accepted: September 20, 2018

Online Published: September 28, 2018

doi:10.20849/ijsn.v3i3.479

URL: https://doi.org/10.20849/ijsn.v3i3.479

\begin{abstract}
The shortage of nurses in Saudi Arabia like many other countries in the world is a problem. Additionally, there are a unique socio-cultural factor that causes the problem including but not limited to the negative perceptions and attitudes towards nurses. Unfortunately, the apprentices are subjected to a system that is inadequately represented by long working hours, negative images, and work pressures. In addition, several factors are attributed to the problems the students face during the initial year of clinical education. This study will analyze and evaluate the different factors that influence the clinical education of the bachelor nursing apprentices, particularly in the first year of experience.
\end{abstract}

Aims and Objectives: The purpose of this study is to explore the factors affecting the clinical practice of nursing interns at tertiary hospital Jeddah.

Methodology and Methods: The research was employed as a qualitative approach. Bachelor nursing students who are currently undertaking their internship program in a tertiary hospital Jeddah) were recruited as participant in this study.

Findings: Data analyses regarding the factors affecting the clinical practice of nursing interns are summarized both positively and negatively. The major theme that emerged that reflects the positive experiences of intern students was "a time for reflection". Further to this the major theme that emerged relating to the challenges experienced by student interns was "cold environment'.

Conclusions: The findings of this research contribute to our understanding of factors affecting the clinical practice of nursing interns. Students identified their clinical learning as cold learning environment because they were treated unfairly, ignored by their instructors and were being embarrassed and feeling restricted. Moreover, students have also identified positive experiences for them during their internship program. The internship program is a great chance for the student for a reflection.

Keywords: clinical challenges, clinical facilitations, clinical practice, factors affecting clinical practice, nursing education in Saudi Arabia, nursing interns, nursing in Saudi Arabia, internship program

\section{Background}

Clinical education enables students to exhibit the practical skills acquired during their study programs both in the real and a controlled environment (Elçigil and Yıldırım 2007). The learning experiences in schools of nursing differ from the internship programs, particularly during the first year of clinical education. Undoubtedly, the clinical environments subject the inexperienced nurses to manifold opportunities of understanding the real practice of caregiving and other patient care operations. Nevertheless, the opportunities are exploited against a background of a multitude of challenges and new disturbing experiences. In most cases, the situation is accompanied by unique issues and endeavors that are different from the class work and conditions of the schools. As such, the nursing students have to strive through the challenges and other associated hurdles to succeed through the subsequent career undertakings (Behere etal. 2011). As Carlson et al. (2003) explains, clinical education is the key to gaining the nursing competence and skills that are practically applicable in health care provisions. It is explicit that experienced nurses serve as the role models for the nursing students particularly through modeling, motivation, mentoring, and monitoring programs (Moonagh et al. 2015). Despite the 
opportunities and the ideal conditions for learning, the students have to face the confrontations and challenges and new experiences.

Clinical environments are areas selected in nursing education which motivate and help the students to inculcate professional skills, knowledge and attitudes those of which are essential for nursing care .These are essential to enhance the communication with patients, for making right clinical decisions, to improve problem solving skills and self-understanding (ALthiga et al. 2017). Nevertheless, learning in clinical environments is not only accompanied by various advantages, but at the same time, it can also be unpredictable, stressful, challenging and constantly changing (Baraz et al. 2015). Several factors are attributed to the problems the students face during the initial year of clinical education. For instance, time constraints and set limits that are either subject to tightened deadlines or, sometimes the seniors nursing allocate insufficient time for the apprentices. In fact, in some cases, the trainees are forced to learn through observations and personal initiatives with little or no guidance from the nurses. Nasrin et al. (2012) also argue that the senior nurses may also be the source of troubles as the many of them are often reluctant or adamant to offer help to the learners. The clinical learning process is also affected by the lack of adequate tools, equipment, and facilities that are provided to the students or that available in the health care institutions. Such inadequacies result in inefficiencies and ineffective learning procedures as the students are bound to receive immature experiences and perhaps do not gain the recommended competencies. Cheraghi et al. (2008) added that non-conducive learning environment and the incompetency of the educator are also seriously affecting the apprentices.

Sometimes the tutors are harsh amongst themselves that creates a heightened environment not favorable for learning. In other instances, the conflicts emanate between the senior nurses and the students, where the former seem to be hostile, bagging, unfriendly, or unconcerned. The unique events and situations, therefore, elicit fear and frustrations amongst the young learners who also have limited knowledge on how to deal with such situations. It is also overwhelmingly challenging because nursing students are expected to gain competence and experience from diverse angles including the physical condition, social, cultural, psychological, and educational means (Pearcey and Draper 2008). According to Singh et al. (2011), nursing students face multiple challenges and stressors worse than students in other disciplines. Worst still, the learners often have limited skills to cope with the stress and situations associated with the clinical education or healthcare institutions. In most cases, the students' roles and contributions to the health care provisions are often regarded as free, cheap, and sometimes uncalled for. As a result, they are forced to follow but not take part. As Cheraghi et al. (2008) reveals, some instructors feel uncomfortable working with the students or even keep them away. Evidence shows that students complain about the lack of attention from the instructors, which subject them to unsatisfactory experiences. The problems are even exacerbated in countries with shortages of nurses and with unique social-cultural perceptions towards nurses such as in Saudi Arabia.

Saudi Arabia is one of the many countries in the world that is struggling with the problem of nursing shortages. For example, the statistics by the World Health Organization in 2004 showed that there were only 40 nurses in every 10, 000 people in Saudi Arabia (Lamadah and Sayed 2014). Further, the standing has becomes worsened in the recent years due to the increased human conflicts and migration of people. In 2010, it was noted that the continuous shortage of nurses in the country had increased by 30\% compared to the 2004 measures. The shortage of nurses is attributed to the migration of people and nurses themselves. Additionally, there are unique socio-cultural factors that cause the problem including but not limited to the negative perceptions and attitudes towards nurses. The problems insightfully reveal that there is a wide opportunity for the government to train more nurses. Unfortunately, the apprentices are subjected to a system that is inadequately represented accompanied by long working hours, negative images, and work pressures. Currently, only about $40 \%$ of the nurses are citizens of Saudi Arabia and the others are from other countries (Lamadah and Sayed 2014). The difference between the socio-cultural background of the local apprentices and the senior foreign nurses also creates challenges to the former. Furthermore, the differences in languages or communication patterns between the trainees and the instructors pose more problems yet to be solved.

\section{Significance of the Study}

Undoubtedly, many research and development activities have been conducted in Saudi Arabia concerning improving the nursing care and practice. However, no study has touched on assessing and evaluating the factors and issues affecting clinical education amid this era where more nurses are needed. The requisition is not only about increasing the numbers of the nurses, but passing them through sufficient and complete education and learning experiences. Unfortunately, there is a big gap in Saudi Arabia, where nursing students experience few opportunities against a backdrop of many challenges. Carlson et al. (2003) reported that the first year of clinical 
education, the learners get subjected to various challenges including stress, hostility from the seniors, long working hours, disregards, and poor communications amongst many more.

Despite the contributions of the previous studies towards nursing education, care, and practice, no study considers this problem. As such, this study is necessary. It is imperative to analyze and evaluate the different factors that influence the clinical education of the bachelor nursing students apprentices, particularly in the first year of experience. Such discoveries coupled with identifying the core challenges that the students face help in devising better mechanisms and systems of clinical education. With that, there will be the production of adequate and competent nurses in Saudi Arabia. This research is an eye opener to the people and government of Saudi Arabia to guide an institution of new modalities of enhancing nursing education and practice.

Therefore, as hinted, this study will contribute to the assessment and evaluation of the problems that nursing apprentices face and the factors that facilitate the effect of clinical education. The focus on the trainees will reveal the hindrances to nursing education, learning, and practices. Undeniably, Saudi Arabia faces challenges and shortages of nurses and nursing services; hence, competent and completely trained new nurses are required. The chapter discloses issues such as inadequate training, mentoring, motivation, and monitoring of nursing students as negatively affecting the Saudi Arabia's nursing practice. The study will inform a multitude of stakeholders including the government, education, nursing, and health care institutions

\section{Aim of the Study}

The purpose of this study is to explore the factors affecting the clinical practice of nursing interns at tertiary hospital

\section{Specific Objectives}

The objectives of the study are to:

1. Explore the factors that facilitate the clinical practice of nursing interns

2. Explore the challenges that influencing the Saudi nursing interns in clinical practice

\section{Methodology}

\subsection{Study Setting}

The College of Nursing, Jeddah at King Saud bin Abdul-Aziz University for Health Sciences will be the setting for this study. The college offers an undergraduate (Baccalaureate) Program in Nursing Science, catering for high school graduates and extends over a period of 4 years. The program is preceded by a foundation program of one year, and followed by internship program of one year length. The aim of the program is graduating independent, critical thinkers who are able to care for the patient, families and communities by providing care that is of the highest standard possible.

\subsection{Study Subjects}

Bachelor nursing students who are currently undertaking their internship program in the tertiary hospital Jeddah will be recruited as participants in this study

The inclusion criteria for the participation are:

1. Students who are willing to participate in this study.

\subsection{Study Design}

The research will employ a qualitative approach to explore the factors affecting the clinical practice of nursing interns at tertiary hospital Jeddah in Saudi Arabia. Qualitative research was developed for use in the social and behavioural sciences to focus on exploring individual and group behaviour in terms of knowledge, attitudes, beliefs and fears, in order to gain an understanding of the meaning and experiences of human life (Burns and Grove, 2005; Creswell 2009; Fossey, Harvey, Mcdermott \& Davidson, 2002). Qualitative methods fit under the post-positivism paradigm, since the reality is dependent on how a person perceives it to be and knowledge is seen as dependent on how people create meanings.

\subsection{Academic Rigour}

\subsubsection{Trustworthiness}

The trustworthiness or the degree of confidence in this qualitative study has been achieved. This study followed the criteria that has been outlined by Lincoln and Guba (1985) and described by Polit and Beck (2010) as the gold standard for qualitative research, which are credibility, transferability, dependability and confirmability. 


\subsubsection{Credibility}

Credibility or the quality of this study to be trusted and believable was achieved through providing feedback to the participant during the interview and confirm their meaning.

\subsubsection{Transferability}

The transferability is the degree in which the results of this study can be generalized and transferred to other contexts also has been achieved through describing the study processes in details, which known as "thick description".

\subsubsection{Dependability}

The stability of this study data over time and conditions has also been managed through providing detailed methodological description, which could assess in the replication process of this study.

\subsubsection{Confirmability}

Researchers have sought to achieve the conformability in this qualitative study by collecting data by interviews. These interviews were audit and notes or other observations have been taken from participant during the interviews. This will allow for the objectivity of the data and ensure that the two independent people will have the same opinions regarding the accuracy of the data.

\subsubsection{Sample Size}

The data collection started off with 2-3 nursing student interns and the sample size was increased until data saturation has been reached.

\subsubsection{Sampling Technique}

Purposive sampling technique was used in this study. Purposive sampling means the researcher deliberately selects specific people or events because they are seen as instances to produce the most relevant data (Denscombe 1998). Thus, purposive sampling was used in this study in order to select participants who will provide the most valuable data about the clinical environment. In addition, theoretical sampling is other form of sampling technique that was used in this study, which means "the selection of instances follows a route of discovery based on the development of a theory which is grounded in evidence" (Denscombe 1998).

Potential participants were identified through the list of all student interns at the hospital. Those potential participants were contacted and notified of the meetings to be held at the College. Then special meetings were conducted to present the study information. At each meeting a sign-up sheet was circulated requesting interested student name and phone numbers. After the meeting follow-up phone calls was made to continue the research processes.

\subsection{Data Collection Methods, Instruments Used, Measurements}

Semi-structured interviews were chosen for this study as the most suitable method of collecting qualitative data and provide the researcher with some control over the questions asked during the interview process and yet provides freedom in terms of expression, allowing the interns to express their views on the phenomena of interest itself at tertiary hospital. Thus, by using semi-structured interviews, the researcher retained some level of control over the study but provided the participants with enough flexibility to elicit detailed subjective responses for a rich source of data. In addition, the interview questions will be unstructured enough to allow the discovery of new ideas and themes. The interviews will take 45-60 minutes in length and will be undertaken in conference room in the college of nursing.

Examples of the research questions:

1. What are the factors affecting you as nursing intern in the clinical practice?

2. What are the factors that facilitate your clinical practice during the internship program?

3. What are the challenges that influence the internship students in the clinical practice?

\subsection{Data Management and Analysis Plan}

Qualitative data analysis was involving the following steps of content analysis:

- Copy and read through the transcript - make brief notes in the margin when interesting or relevant information is found.

- Go through the notes made in the margins and list the different types of information found.

- Read through the list and categorize each item in a way that offers a description of what it is about. 
- Identify whether or not the categories can be linked any way and list them as major categories (or themes) and / or minor categories (or themes)

- Compare and contrast the various major and minor categories

- If there is more than one transcript, repeat the first five stages again for each transcript

- When you have done the above with all of the transcripts, collect all of the categories or themes and examine each in detail and consider if it fits and its relevance

- Once all the transcript data is categorized into minor and major categories/themes, review in order to ensure that the information is categorized as it should be.

- Review all of the categories and ascertain whether some categories can be merged or if some need to them be sub-categorized

- Return to the original transcripts and ensure that all the information that needs to be categorized has been so (Neuendorf, 2002).

5.7 Data Analysis

\begin{tabular}{ll}
\hline Themes & subthemes \\
\hline Cold environment & unfair treatment \\
& feeling ignored \\
& Being embarrassed \\
& Feeling restricted. \\
A time for reflection & future possibilities \\
& ownership of learning \\
\hline
\end{tabular}

\section{Results}

Seven participants, who met the inclusion criteria, were recruited for the study. All participants were female, stream I, had their internship program at tertiary hospital. Their age was between 23-25 years old.

\section{Findings}

Data analysis regarding the factors affecting the clinical practice of nursing interns was summarized both positively and negatively. The major theme that emerged that reflects the facilitation for intern students during their clinical practices was A time for reflection with subthemes are future possibilities, ownership of learning and personal growth.

\section{A Time for Reflection}

\subsection{Future Possibilities}

Students verbalized that rotating between the different areas within clinical placements allowed them the opportunity to reflect about where they wanted to be placed during the second part of their clinical rotations:

Student 4: Of course going to different areas in phase I was very good, it allow for me to have a clear idea about what I want to do and where to work. I started maternity ward in the second rotation but I was wanted to see other area before I decide then when I passed through all areas I decided to be in the maternity.

Student 3: Then I move to the maternity ward it was short time just two week but it was enough to give an overview idea about this ward, it was good experience.

\section{a. Ownership of learning}

Some students verbalized that the internship period create opportunities for them to take responsibility for the learning by showing initiative and interest:

Student 3: Another factors is the student herself if she want to learn something she will learn it, she can Google, asking questions, go to the doctors' round.

Student 2: Some of the student when the doctor came to see the patient her preceptor go with the doctor to the patient room and the student stay on the station why? Is that your patient or not? Go and hear what is happening, she has to involve herself in everything, listen to the plan 


\section{b. Personal growth}

Students verbalized that the internship helped them to develop personal skills such as communication and leadership skills especially when dealing with different people:

Participant 7: In the personal skills added to my characteristic, the first thing is communication skill, either I communicate with patients, with staff, with doctors. As we know we have different characteristics of people, and this is the most common thing what I learned.

Participant 7: And the first thing what add to my personal characteristic is leadership, how to be managed, how to be memorized, how to be recognized everything. And also other things to add to my experience is time management, how to be planned of my work, how to be prioritize my thing, what I will do now, what I will do later, what I will do... In the beginning of my intern, it was complicated because I didn't know what I will do now, what I will do...

The major theme that emerged reflecting the challenges experienced by student interns was " cold environment' with subthemes : unfair treatment; being ignored; being embarrassed; and feeling restricted.

\section{Cold Environment}

\subsection{Unfair Treatment}

Students highlighted that during clinical placements, treatment of them by unit managers and primary nurses were often perceived as strict and unfair.

Participants 1: The nurse manager was very strict with us .... was stricter with us than other staff. For example, if she saw me on the computer she asked me "why you are not with your PCT (patient clinical technician)" I told her "she asked me to put some data on quadramed. And she is doing something else. She said "no, you have to follow her" but sometime she just collect some equipment from the dressing room "why I have to follow her it is not necessary I can do another thing". She said "no you have to follow her".

Participants 2: For example, some time I heard that my friends are absent too much without any notice and no one talk to them. On the other hand, some students absent for the first time and the coordinators discover that they punish you even if the first time and you are excellent. It is unfairness.

Participant 6: The manager didn't like me and one of our friends as well, she didn't treat us well at all, in the mid-evaluation she asked me about the names of the equipment's and that's it, and I was under so much stress from her that I forgot the name of the "Inco pad" and she told me: you don't even have the basic knowledge. So, later in my end evaluation I told the intern's coordinators that the manager will not be fair to me if she was the one who will do my evaluation, and the coordinator talked to her then the evaluation went well. However, the mid evaluation was bad because of that incident.

\subsection{Feeling Ignored}

Some students verbalized that during some rotations within the clinical placements they felt ignored by staff.

Participant 2: My preceptor had a bad experience from previous students and she thought all students intern are the same. So, when I started with her I feel I am working alone and she worked alone also

Students also verbalised that staff ignored them and were not willing to teach them:

Participant 2: The problem of the preceptors also challenges for us. They ignore us totally like they do not know they have intern students and they are responsible for them. They did not teach anything and they always said "you have to be independent".

Participant 6: In the medical ward the nurses did not want to teach us anything they just call us when they need someone to do the vital signs and in the bed bath only, in these two things they call us otherwise they ignore us.

Another student expressed feeling invisible towards the preceptors. She also expressed a feeling of exclusion as the preceptor refused to include the intern even after help was offered:

Participant 3: Some of the preceptors they are dealing with us like we are invisible she does not want anyone to help her or do what she supposed to do she refused help from intern students.

Student 6: Some of the preceptors are not cooperative with us because they don't have time for us. Especially in Medical (Ward 5), one preceptor would have 6 patients with her which don't allow her to find time to teach and answer our questions or even sign our competencies. 


\subsection{Being Embarrassed}

Being embarrassed within the clinical area was expressed by students. One student verbalized that she was confronted by the nurse manager in the presence of the doctors which resulted in her feeling embarrassed and worthless:

Participant 2: One time I have a very embarrassing situation, my nurse asked me to bring the glucometer to measure the patient's blood sugar; I went to bring it and the nurse manager saw me and stop me asked "who are you"? I told her "I am nurse intern and my preceptor asked me to bring the glucometer". She said "you should be with her". I told her "I am with her but she sent me to bring this". She said "no she should bring it and you follow her". All this conversation was in front of the doctors, they will see me nothing.

\subsection{Feeling Restricted}

Many students highlighted that they were restricted to only certain tasks during patient care. Most of the times, they were allowed to engage in tasks that involved basic skills other than advanced skills appropriate to the internship level:

Participant 1: In general for the all .... in where they call us like PCT just to take vital signs and the bed bath and this is in the most of the wards. So, I just do the vital signs and then enter in quadramed then I do not have anything to do,

Participant 4: I mean when they saw a new student they give us only the vital sign to do nothing else they are not involving us in any other procedure.

In addition, students also verbalized that they felt the need to do other nursing skills other than the basic skills of bed bathing and vital signs:

Participant 1: I told the PCT "this is your job to take the vital signs and I will do something else" she went to the charge nurse and complained and the charge nurse went to the intern coordinator and informed her. The coordinator told me "I cannot do anything but if she asked you to take the vital signs you have to take it". I said "I do not have any problem I will take but not all my duty just for vital signs I want to feel I am nurse to do something different than vital signs and bed bath".

Further to this the major theme that emerged relating to the positive experiences of intern students was "a time for reflection"

\section{Discussion}

Nurses represent the nucleus of the health care systems as they play a leading role in the prevention and treatment of related health conditions. As a result, the country needs competent nurses who are well trained and ready to care for people. The unfortunate scenario in Saudi Arabia calls for adjustments as better learning environments and experiences should be provided for the nursing students. To do that, it requires a prerequisite knowledge of the key factors that affect them and the challenges they go through, which this study offers.

The first theme that emerged during the study was centered around positive ideas in the student as 'A time of reflection' with subthemes on 'future possibilities', 'ownership of learning' and 'personal growth'.

Students felt that during the clinical placements, they had a psycho-social experience whilst being in the original setting that helped them refine their career prospects. Happell (1999) found that undergraduate nursing students have firm pre-conceived ideas as to areas of choice for future practice. The clinical internship process offers them an opportunity to have a closer look and to build insight required to form a career decision.

Students also felt that the learning process in the clinical setting is subjective to their own interest which encouraged them to take initiatives. This was a positive outcome of their learning experience in the clinical area. In addition to this, the students also felt that the setting for clinical training was breeding grounds for communication and leadership skills, which they felt was developed in them during their completed experience. Stress therefore, builds coping skills in nursing students (Mahatt, 1998). Such skills already attained by the students in the internship phase will equip them to effectively deal with numerous stresses and challenges faced by graduates during their transition from student nurse to a practicing professional nurse (Casey et. al, 2004).

The constraints in the clinical learning was identified as cold surrounding where the students felt that they were unfairly treated that affected their conduct and overall experience. Anger invoked by 'Perceived unjustice' is reported by nursing students more often in clinical education rather than classroom education (Thomas, 2009). The present study shows that intensity of such incidents with nursing students, outlined by behaviors which may 
be seen as degradotary, disrespectful, overbearing and condescending are reported in a continuum. Also it is seen that the students were affected adversely with the behavior and related it to personal targeting.

Another aspect of the cold educational setting was a continuous sense of being ignored and unacknowledged as relayed on by the students. They felt that the preceptor was dismissive and discouraging. This led to a perception among the students that the staff is not willing to teach them what they needed to learn as basic skills. Secrest et al (2003) spoke of an increased sense of alienation in nursing students, which paves way to a feeling of demeaning, and ignorance in them. Such an environment affects the student's approach towards learning and decreases the inquisitional instincts. This in turn results in an environment where the learner is restricted to voice his query (Russell et. al, 2006) which is an evident downfall of such a setting.

The cold and unwelcoming clinical areas are often grounds to incidents which embarrass the students and lay a negative impact on their self-esteem. The narratives in this refer to the context (1.2) show that the student was very aware of power balance in the environment and felt intimidated by the experience. This cultivates suppressed anger as the student is unable to engage in a dialogue or an opportunity to solve the problem with the provocateur (Thomas, 2009; Thomas, 2008). The researchers observed that the students felt that the opportunities for them to grow in the learning environment and engage in the skill level required as per their internship level are few and deficient. Certain factors need to be addressed in areas of student involvement, satisfaction and personalization by way of implementation of another tested model of clinical learning e.g. 'preceptor model'(Henderson et. al, 2006).

\section{Conclusions}

The findings from this research highlights that nursing interns are often faced with a variety of factors that can either positively or negatively affect their learning. As emerged in this study students identified their clinical learning as cold learning environment because they were treated unfairly, ignored by their instructors, were embarrassed and felt restricted. However, students have also identified positive experiences such as personal growth and leadership which creates opportunities for them to become independent practitioners. Lastly, the internship program is an ideal context in order for students to reflect on their learning.

\section{References}

Althiga, H., Mohidin, S., Park, Y.S., \& Tekian, A. (2017). Preparing for practice: Nursing intern and faculty perceptions on clinical experiences. Med Teach, 39(sup1), S55-S62.

Baraz, S., Memarian, R., \& Vanaki, Z. (2015). Learning challenges of nursing students in clinical environments: A qualitative study in Iran. Journal of Education and Health Promotion, 4, 52. https://doi.org/10.4103/2277-9531.162345

Behere, S.P., Yadav, R., \& Behere, P.B. (2011). A comparative study of stress among students of medicine, engineering and nursing. Indian Journal of Psychological Medicine, 33(2), 145-148.

Burns, N., \& Grove, S.K. (2005). The Practice of Nursing Research Conduct, Critique and Utilization (5th ed.). Elsevier Saunders, Missouri.

Carlson, S., Kotze, W., \& Rooyen, D. (2003). Accompaniment needs of first year nursing students in the clinical learning environment. Curationis, 26(2), 30-39. https://doi.org/10.4102/curationis.v26i2.778

Casey, K., Fink, R.R., Krugman, A.M., \& Propst, F.J. (2004). The graduate nurse experience. Journal of Nursing Administration, 34(6), 303-311. https://doi.org/10.1097/00005110-200406000-00010

Cheraghi, M., Salasli, M., \& Ahmadi, F. (2008). Factors influencing the clinical preparation of BS nursing student interns in Iran. International Journal of Nursing Practice, 14(1), 26-33. https://doi.org/10.1111/j.1440-172X.2007.00664.x

Creswell, J.W. (2009). Research Design: Qualitative, Quantitative, and Mixed Methods Approaches. SAGE Publications.

Denscombe, M. (1998). The good research guide: For small-scale social research projects. Philadelphia: Open University Press.

Elçigil, A., \& Yıldırım , H. (2007). Determining problems experienced by student nurses in their work with clinical educators in Turkey. Nurse Education Today, 27, 491-498. https://doi.org/10.1016/j.nedt.2006.08.011 
Fossey, E., Harvey, C., Mcdermott, F., \& Davidson, L. (2002). Understanding and Evaluating qualitative research. Australian \& New Zealand Journal of Psychiatry, 36(6), 717-732. https://doi.org/10.1046/j.1440-1614.2002.01100.x

Happell, B. (1999). When I grow up I want to be a...? Where undergraduate student nurses want to work after $\begin{array}{llll}\text { graduation. } \quad \text { Journalof } & \text { Advanced }\end{array}$ https://doi.org/10.1046/j.1365-2648.1999.00913.x

Henderson, A., Twentyman, M., Heel, A., \& Lloyd, B. (2006). Students' perception of the psycho-social clinical learning environment: an evaluation of placement models. Nurse Education Today, 26(7), 564-571. https://doi.org/10.1016/j.nedt.2006.01.012

Lamadah, S., \& Sayed, H. (2014). Journal of Biology, Agriculture and Healthcare. Challenges Facing Nursing Profession in Saudi Arabia, 4(7), 20-25.

Lincoln, Y.S., \& Guba, E.G. (1985). Naturalistic Inquiry. Newbury Park, CA: Sage Publications.

Mahat, G. (1998). Stress and coping: junior baccalaureate nursing students in clinical settings. In Nursing forum, 33(1), 11-19. Blackwell Publishing Ltd. https://doi.org/10.1111/j.1744-6198.1998.tb00976.x

Moonaghi, H., Mirhaghi, A., Olad, S., \& Zeydi, A. (2015). A Journey across an Unwelcoming Field: A Qualitative Study Exploring the Factors Influencing Nursing Students' Clinical Education. Health Science Journal, 9(4), 1-6.

Nasrin, H., Soroor, P., \& Soodabeh, J. (2012). Nursing Challenges in Motivating Nursing Students through Clinical Education: A Grounded Theory Study. Nursing Research and Practice, 1-7. https://doi.org/10.1155/2012/161359

Neuendorf,K.A.(2002). The content Analysis Guidebook. SAGE.

Pearcey, P., \& Draper, P. (2008). Exploring clinical nursing experiences: listening to student nurses. Nurse Educ. Today, 28, 595-601. https://doi.org/10.1016/j.nedt.2007.09.007

Polit, D.F., \& Beck, C.T. (2010). Essentials of Nursing Research: Appraising Evidence for Nursing Practice. Lippincott Willliams \& Wilkins.

Russell, L., Nyhof-Young, J., Abosh, B., \& Robinson, S. (2006). An exploratory analysis of an interprofessional learning environment in two hospital clinical teaching units. Journal of Interprofessional Care, 20(1), 29-39. https://doi.org/10.1080/13561820500476473

Secrest, J.A., Norwood, B.R., \& Keatley, V.M. (2003). I was actually a nurse: The meaning of professionalism for baccalaureate nursing students. Journal of Nursing Education, 42(2), 77-82.

Singh, C., Sharma, S., \& Sharma, R. (2011). Level of stress and coping strategies used by nursing interns. Nursing and Midwifery Research Journal, 7(4), 152-160.

Thomas, S.P. (2008). Transforming nurses' stress and anger: Steps toward healing. Springer Publishing Company.

Thomas, S.P., \& Burk, R. (2009). Junior nursing students' experiences of vertical violence during clinical rotations. Nursing outlook, 57(4), 226-231. https://doi.org/10.1016/j.outlook.2008.08.004

\section{Copyrights}

Copyright for this article is retained by the author(s), with first publication rights granted to the journal.

This is an open-access article distributed under the terms and conditions of the Creative Commons Attribution license (http://creativecommons.org/licenses/by/4.0/). 